\title{
Effect of Pressure on the Superconducting and Mechanical Properties of $\mathrm{Bi}_{1.6} \mathrm{~Pb}_{0.4} \mathrm{Sr}_{1.8} \mathrm{Ba}_{0.2} \mathrm{Ca}_{2} \mathrm{Cu}_{2.2} \mathrm{Ni}_{0.8} \mathrm{O}_{10+\delta} \mathrm{System}$
}

\author{
Ghazala Y. Hermiz ${ }^{*}$ Bushra A. Aljurani, Hassan A. Thabit \\ Physics Department, College of Science, University of Baghdad, Baghdad, Iraq \\ Email: "gyhermiz@yahoo.com
}

Received January 4, 2013; revised February 7, 2013; accepted February 17, 2013

\begin{abstract}
Solid state reaction method was used to prepare samples of $\mathrm{Bi}_{1.6} \mathrm{~Pb}_{0.4} \mathrm{Sr}_{1.8} \mathrm{Ba}_{0.2} \mathrm{Ca}_{2} \mathrm{Cu}_{2.2} \mathrm{Ni}_{0.8} \mathrm{O}_{10+\delta}$. Superconducting and mechanical properties by Vickers microhardness measurements have been carried out to examine the effects of pressure. Electrical measurement demonstrates the best transition temperature was under $0.7 \mathrm{GPa}$. An improvement of mechanical properties was found when the pressure increases from $0.3 \mathrm{GPa}$ to $0.9 \mathrm{GPa}$. On the other side an increases of the pressure to $1.1 \mathrm{GPa}$ decrease in the micro hardness, Young modulus and yield strength.
\end{abstract}

Keywords: Pressure Effect; Superconductor; Mechanical Properties

\section{Introduction}

Considerable efforts have been made in the synthesis, processing, and characterization of $\mathrm{BiSrCaCuO}$ superconducting ceramics because these materials have a higher $\mathrm{T}_{\mathrm{c}}$ and good chemical durability (resistance to moisture), and also they contain no rare earth elements [1-3]. However, the bulks sometimes fracture due to the thermal stress on the cooling process or the electromagnetic force during the magnetization. Thus, it has been recognized that improvement and understanding of the mechanical properties of bulks are indispensable for practical application.

Ahn [4] prepared superconducting $\mathrm{BiSrCaCu}(\mathrm{Ni}) \mathrm{O}$ ceramics by the gel method using an aqueous solution containing a tartaric acid. Their ceramic microstructure were studied using IR, TGA, XRD, resistance measurements, and SEM. They found that the nickel dopant substituting for $\mathrm{Cu}$ gives rise to the gradual decrease of the $\mathrm{T}_{\mathrm{c}}$ and the pure phase 2212 ceramics were obtained at sintering temperature $1098 \mathrm{~K}$ for $24 \mathrm{hs}$. SEM pictures showed that liquid phase was formed when the samples were sintered temperatures higher than $1098 \mathrm{~K}$.

The effect of silver additions on the mechanical and superconducting properties of sintered bulk YBCO, BSCCO-2212, and BSCCO-2223 has been evaluated by Joo et al. [5] their results show that strength and fracture toughness of YBCO and BSCCO bars increased with increasing Ag content up to $30 \mathrm{vol} \% \mathrm{Ag}$. These im-

${ }^{*}$ Corresponding author. provements in strength and fracture toughness are due to the presence of Ag particles that may induce compressive stresses in the superconducting matrix and resist crack propagation by pinning the propagating cracks. On the other hand, the hardness of YBCO and BSCCO decreased with increasing $\mathrm{Ag}$ contents because of the lower hardness of Ag. Addition of Ag showed no adverse effects on superconducting properties of YBCO or BSCCO superconductors.

Katagiri et al. [6] summarize the evaluation process of the mechanical properties for various high-temperature superconducting bulks. The Young's modulus, Poisson's ratio, fracture strength, fracture toughness and hardness are evaluated by tensile, bending, compression and hardness tests. The mechanical properties are anisotropic, mainly due to the crystallographic structure and pre-existing micro-cracks associated with it.

Madre et al. [7] measured the flexural strength of 1 wt $\%$ Ag-doped $\mathrm{Bi}_{2} \mathrm{Sr}_{2} \mathrm{CaCu}_{2} \mathrm{O}_{8+\delta}$ thin rods textured by a laser heated floating zone as a function of the environmental conditions (air versus water) at room temperature. Loading rates spanning three orders of magnitude $(1,10$ and $100 \mu \mathrm{m} / \mathrm{min}$ ) were used to explore their susceptibility to the environmental conditions. These mechanical tests were completed with electrical characterization (critical current at $77 \mathrm{~K}$ and resistivity from 77 to $300 \mathrm{~K}$ ) of samples submerged in distilled water for different time lengths $(0,12$ and $120 \mathrm{~h})$. While $\mathrm{Bi}_{2} \mathrm{Sr}_{2} \mathrm{CaCu}_{2} \mathrm{O}_{8+\delta}$ has been shown to be unstable during contact with water molecules, the Ag-doped Bi-2212 textured rods tested 
are very inert to the water environment, with respect to their mechanical and electrical properties, due to the presence of a narrow $(\approx 150 \mu \mathrm{m})$ low textured outer ring formed in the growth process.

In the previous work [8], mechanical properties of $\mathrm{Bi}_{1.6} \mathrm{~Pb}_{0.4} \mathrm{Sr}_{1.8} \mathrm{Ba}_{0.2} \mathrm{Ca}_{2} \mathrm{Cu}_{2.2} \mathrm{Ni}_{0.8} \mathrm{O}_{10+\delta}$ superconducting system pressed under $0.5 \mathrm{GPa}$ were investigated. In this research, effect of pressure on the critical temperature $\left(\mathrm{T}_{\mathrm{c}}\right)$, oxygen content $(\delta)$ and mechanical properties of the superconducting system have been studied.

\section{Experimental Part}

$\mathrm{Bi}_{1.6} \mathrm{~Pb}_{0.4} \mathrm{Sr}_{1.8} \mathrm{Ba}_{0.2} \mathrm{Ca}_{2} \mathrm{Cu}_{2.2} \mathrm{Ni}_{0.8} \mathrm{O}_{10+\delta}$ samples were prepared by conventional solid-state reaction method. Appropriate amounts of $\mathrm{Bi}_{2} \mathrm{O}_{3}(99.9 \%), \mathrm{Pb}_{3} \mathrm{O}_{4}(99.9 \%), \mathrm{SrCO}_{3}$ (99.9\%), $\mathrm{BaCO}_{3}(99.9 \%), \mathrm{CaO}(99.9 \%), \mathrm{CuO}(99.9 \%)$ and $\mathrm{Ni}_{2} \mathrm{O}_{3}(99.9 \%)$ powders were used as starting mate- rials. The powder of precursor was mixed together by using agate mortar. The mixture homogenization takes place by adding a sufficient quantity of 2 - propanol to form a past during the process of grinding from about $(1 \mathrm{~h})$. In the second step, the materials were grounded to a fine powder and then calcined in air at $1073 \mathrm{~K}$ for $24 \mathrm{hs}$, the mixture was then pressed into pellets $(1.3 \mathrm{~cm})$ in dia- meter and $(0.2) \mathrm{cm}$ thick, using hydraulic type (SPECAC), under pressure of $0.3,0.5,0.7,0.9$ and $1.1 \mathrm{GPa}$. The pellets were sintered in air at $1123 \mathrm{~K}$ for $140 \mathrm{hs}$.

Iodometric titration was used to find the oxygen content $(\delta)$ in the samples. Four probe dc method at temperature range $(77$ - 300) $\mathrm{K}$ was used to measure the resistivity $(\rho)$ and to determine the critical temperature $\left(\mathrm{T}_{\mathrm{c}}\right)$.

The mechanical properties, such as the Vickers microhardness $\left(\mathrm{H}_{\mathrm{V}}\right)$, Young modulus $(\mathrm{E})$ and yield strength $(\mathrm{Y})$ of superconductor samples were calculated as referred in the previous paper [8].

\section{Results and Discussion}

In order to examine the effect of the pressure on critical temperature $\mathrm{T}_{\mathrm{c}}$, samples of $\mathrm{Bi}_{1.6} \mathrm{~Pb}_{0.4} \mathrm{Sr}_{1.8} \mathrm{Ba}_{0.2} \mathrm{Ca}_{2} \mathrm{Cu}_{2.2}$ $\mathrm{Ni}_{0.8} \mathrm{O}_{10+\delta}$ were sintered at $1123 \mathrm{~K}$ for 140 hs under different pressures $(0.3,0.5,0.7,0.9$ and 1.1$) \mathrm{GPa}$. The resistivity behavior as a function of temperature for $\mathrm{Bi}_{1.6}$ $\mathrm{Pb}_{0.4} \mathrm{Sr}_{1.8} \mathrm{Ba}_{0.2} \mathrm{Ca}_{2} \mathrm{Cu}_{2.2} \mathrm{Ni}_{0.8} \mathrm{O}_{10+\delta}$ at different pressures are shown in Figure 1. From this figure we can see the increase of the critical temperature $\mathrm{T}_{\mathrm{c}}$ from $113 \mathrm{~K}$ to $117 \mathrm{~K}$ with increasing pressure from $0.5 \mathrm{GPa}$ and $0.7 \mathrm{GPa}$, while an increase of the pressure to $1.1 \mathrm{GPa}$ causes a reduction of transition temperature to $93 \mathrm{~K}$. It is believed that the increase of the critical temperature with increasing pressure from 0.3 to $0.7 \mathrm{GPa}$, as listed in Table 1 may be due to the increase of the carrier concentration $n_{h}$ in the $\mathrm{CuO}_{2}$ planes, the change of $n_{h}$ within the unit cell resulting in the improvement of the critical temperature [9]. Also Vonsovsky et al. [10] indicate that the deviation from stoichioctry and disordering of these compound lead to decrease the value of $\mathrm{T}_{\mathrm{c}}$ with the pressure.

It is found from Table 1 that the oxygen content $(\delta)$ of the samples increases as the pressure increases. This is clearly shown for samples under $0.3 \mathrm{GPa}, 0.5 \mathrm{GPa}$ and $0.7 \mathrm{GPa}$, the oxygen content $(\delta)$ is $0.191,0.246$ and 0.368 respectively. The enhancement of the pressure is going to enhance the hole concentration in the $\mathrm{Cu}-\mathrm{O}_{2}$ layers, also enhancing the critical temperature $T_{c}$ from nearly 110 , $113 \mathrm{~K}$ to $117 \mathrm{~K}$ respectively, while increases the pressure to $1.1 \mathrm{GPa}$ decreases the oxygen content $(\delta)$ and the critical temperature $T_{c}$ as shown in Figure 2. This indicates that the increase in the critical temperature $T_{c}$ and the oxygen content $(\delta)$ values is attributed to the increase of oxygen absorption during crystallization process of the superconductors. From the results we can conclude that the oxygen content $(\delta)$ equal 0.368 is optimum

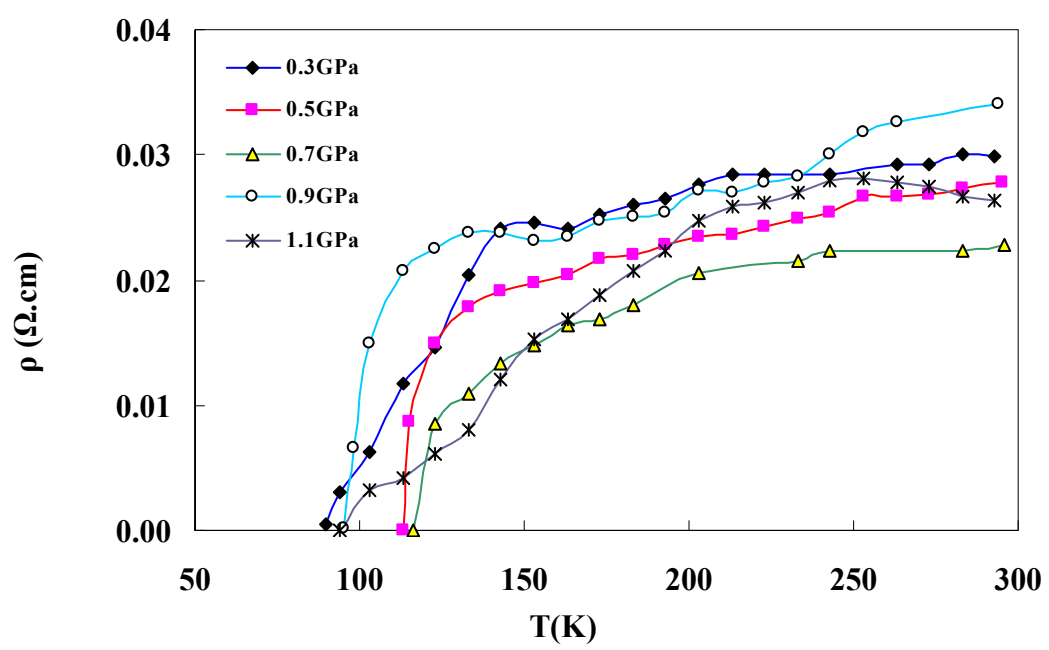

Figure 1. Temperature dependence of resistivity for $\mathrm{Bi}_{1.6} \mathrm{~Pb}_{0.4} \mathrm{Sr}_{1.8} \mathrm{Ba}_{0.2} \mathrm{Ca}_{2} \mathrm{Cu}_{2.2} \mathrm{Ni}_{0.8} \mathrm{O}_{10+\delta}$ under different pressure. 


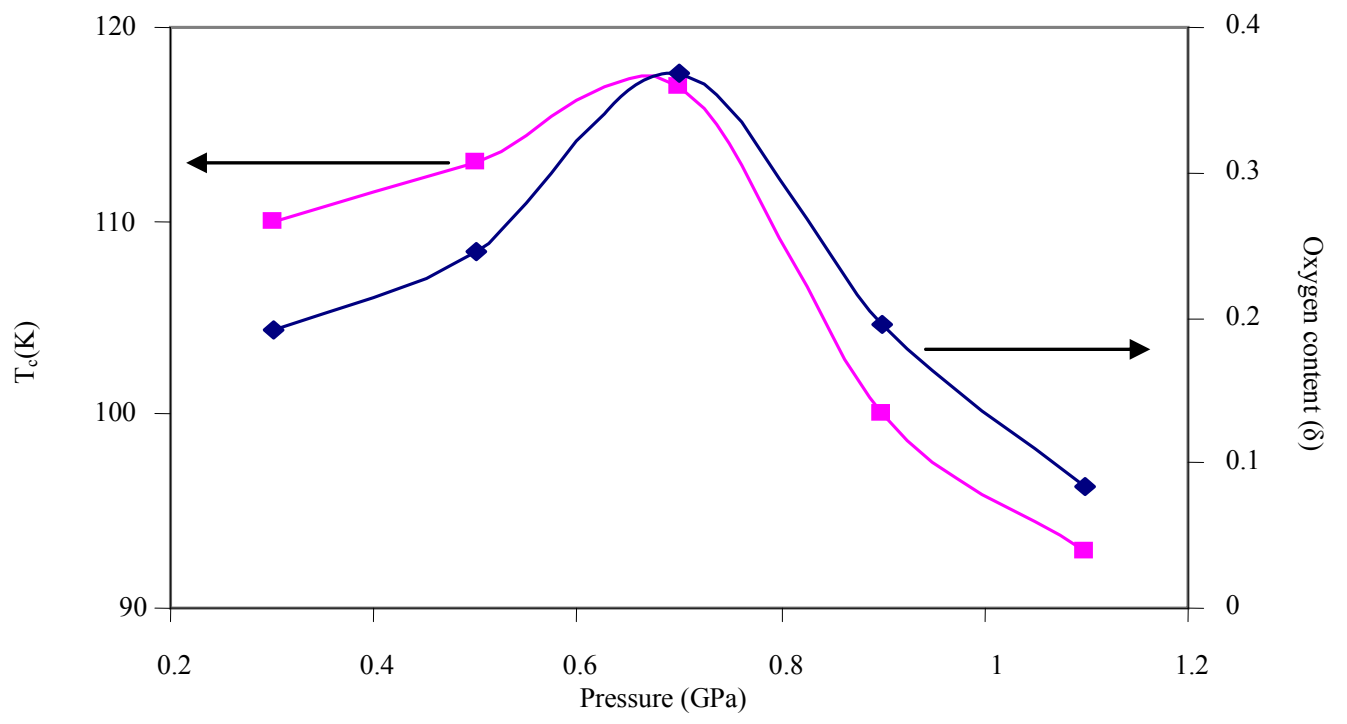

Figure 2. Transition temperature and oxygen content for $\mathrm{Bi}_{1.6} \mathrm{~Pb}_{0.4} \mathrm{Sr}_{1.8} \mathrm{Ba}_{0.2} \mathrm{Ca}_{2} \mathrm{Cu}_{2.2} \mathrm{Ni}_{0.8} \mathrm{O}_{10+\delta}$ under different pressure.

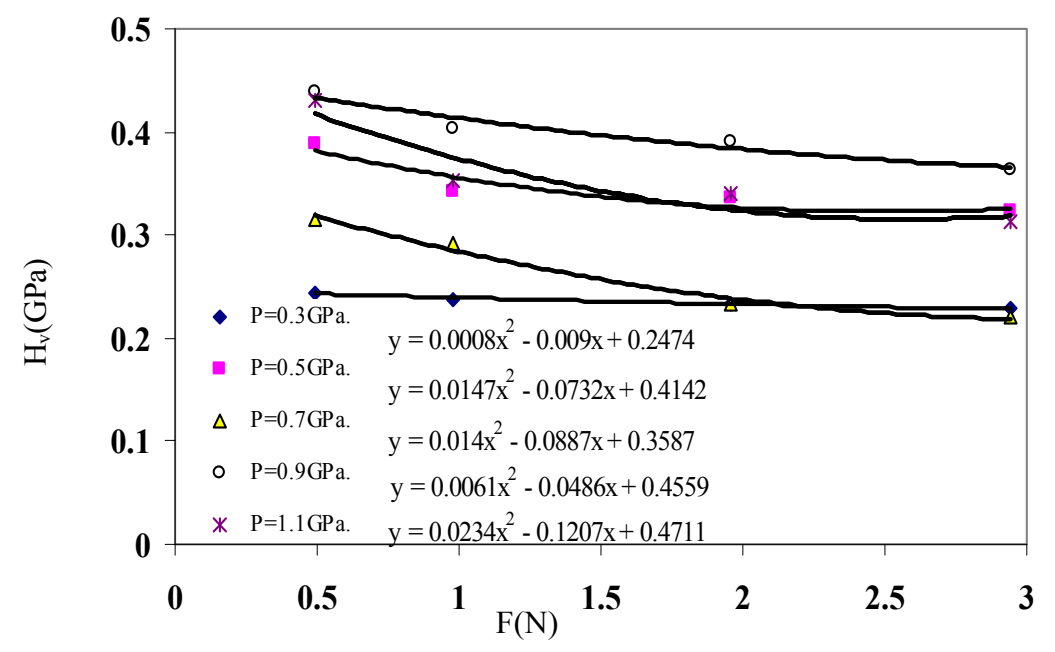

Figure 3. Variation of microhardness with applied load for different pressures.

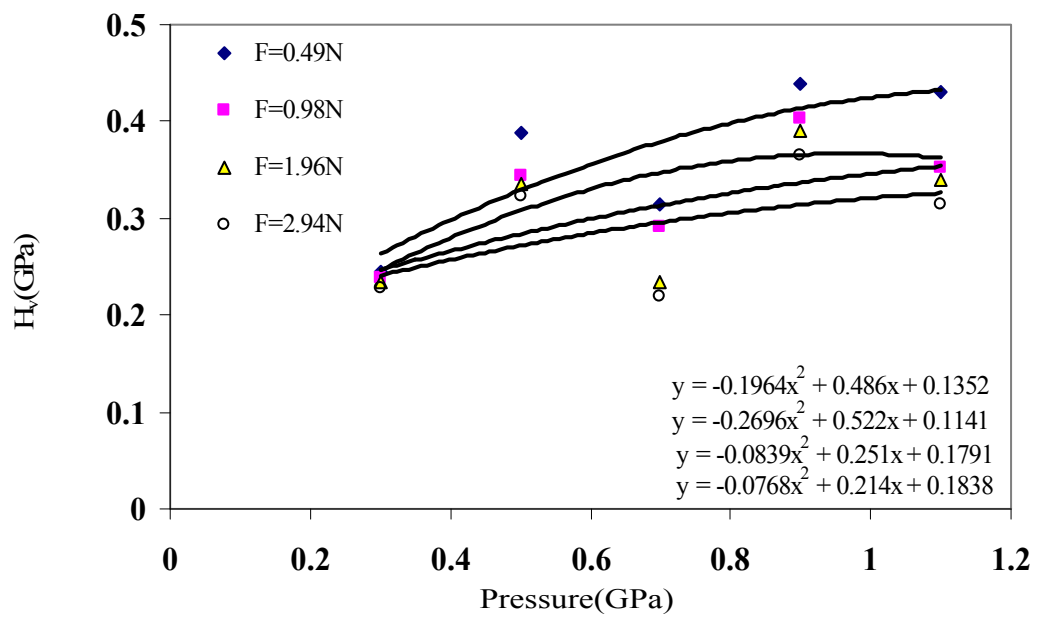

Figure 4. The variations of microhardness $\left(\mathrm{H}_{\mathrm{v}}\right)$ as a function of pressure for different loads. 


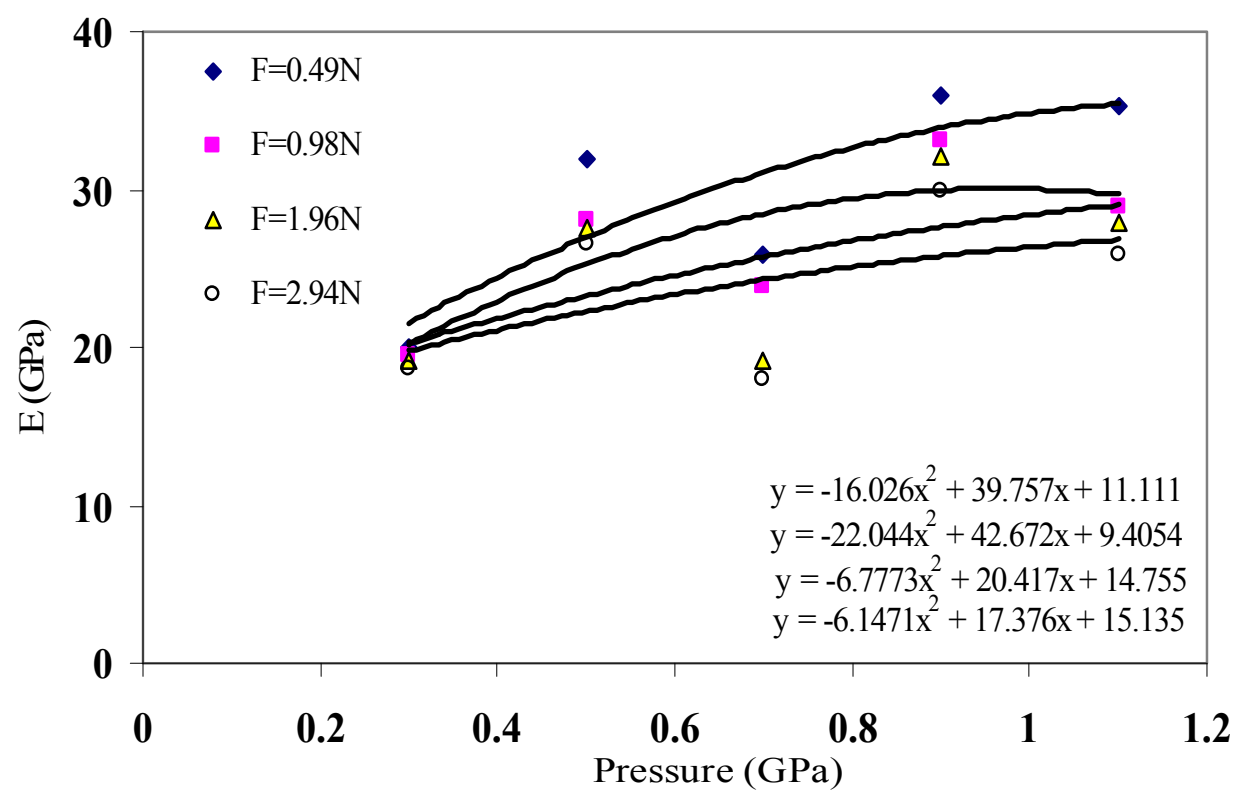

Figure 5. Variations of Young's modulus (E) as a function of pressure for different loads.

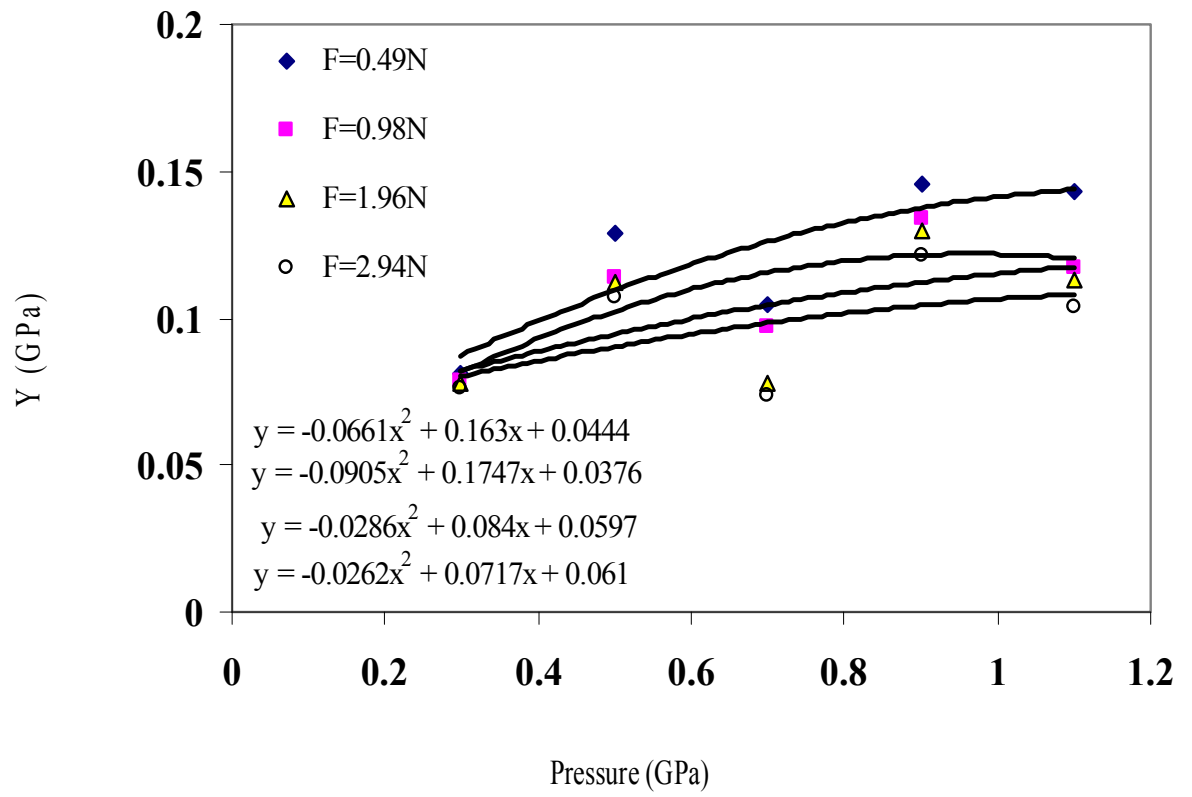

Figure 6. Variations of yield strength $(Y)$ as a function of pressure for different loads.

Table 1. Oxygen content and critical temperature $\left(\mathrm{T}_{\mathrm{c}}\right)$ for $\left(\mathrm{Bi}_{0.8} \mathrm{~Pb}_{0.2}\right)_{2}\left(\mathrm{Sr}_{0.9} \mathrm{Ba}_{0.1}\right)_{2} \mathrm{Ca}_{2} \mathrm{Cu}_{2.2} \mathrm{Ni}_{0.8} \mathrm{O}_{10+\delta}$ under different pressures.

\begin{tabular}{ccc}
\hline Pressure (GPa) & $\boldsymbol{\delta}$ & $\mathbf{T}_{\mathbf{c}}(\mathbf{K})$ \\
\hline 0.3 & 0.191 & 110 \\
0.5 & 0.246 & 113 \\
0.7 & 0.368 & 117 \\
0.9 & 0.196 & 100 \\
\\
1.1 & 0.083 & 93 \\
\hline
\end{tabular}


Table 2. Microhardness $\left(\mathrm{H}_{\mathrm{v}}\right)$, Young modulus (E) and yield strength (Y) for different load for $\mathrm{Bi}_{1.6} \mathrm{~Pb}_{0.4} \mathrm{Sr}_{1.8} \mathrm{Ba}_{0.2} \mathrm{Ca}_{2} \mathrm{Cu}_{2.2}$ $\mathrm{Ni}_{0.8} \mathrm{O}_{10+\delta}$ under different pressure and different loads.

\begin{tabular}{|c|c|c|c|c|}
\hline Pressure (GPa) & $F(N)$ & Hv (GPa) & E (GPa) & Y (GPa) \\
\hline 0.3 & & 0.244 & 20.01 & 0.081 \\
\hline 0.5 & & 0.389 & 31.91 & 0.129 \\
\hline 0.7 & 0.49 & 0.315 & 25.82 & 0.105 \\
\hline 0.9 & & 0.439 & 36.01 & 0.146 \\
\hline 1.1 & & 0.430 & 35.28 & 0.143 \\
\hline 0.3 & & 0.238 & 19.53 & 0.079 \\
\hline 0.5 & & 0.343 & 28.13 & 0.114 \\
\hline 0.7 & 0.98 & 0.292 & 23.93 & 0.0973 \\
\hline 0.9 & & 0.404 & 33.11 & 0.134 \\
\hline 1.1 & & 0.352 & 28.85 & 0.117 \\
\hline 0.3 & & 0.234 & 19.211 & 0.078 \\
\hline 0.5 & & 0.336 & 27.57 & 0.112 \\
\hline 0.7 & 1.96 & 0.234 & 19.18 & 0.078 \\
\hline 0.9 & & 0.391 & 32.07 & 0.130 \\
\hline 1.1 & & 0.340 & 27.89 & 0.113 \\
\hline 0.3 & & 0.228 & 18.72 & 0.076 \\
\hline 0.5 & & 0.323 & 26.52 & 0.107 \\
\hline 0.7 & 2.94 & 0.22 & 18.03 & 0.0733 \\
\hline 0.9 & & 0.364 & 29.90 & 0.121 \\
\hline 1.1 & & 0.314 & 25.80 & 0.104 \\
\hline
\end{tabular}

value for the critical temperature $\mathrm{T}_{\mathrm{c}} 117 \mathrm{~K}$ under pressure $0.7 \mathrm{GPa}$.

The effects of pressure on the mechanical properties of $\mathrm{Bi}_{1.6} \mathrm{~Pb}_{0.4} \mathrm{Sr}_{1.8} \mathrm{Ba}_{0.2} \mathrm{Ca}_{2} \mathrm{Cu}_{2.2} \mathrm{Ni}_{0.8} \mathrm{O}_{10+\delta}$ samples were studied. The samples were pressed under $0.3,0.5,0.7,0.9$ and 1.1 GPa. It is noticed from Figure 3 a decreases of the microhardness with increases of load for samples under different pressures. This behavior may attribute to the presence of weak grain boundaries of the superconducting ceramics.

Figures 4-6 and Table 2 shows the variation of Vickers microhardness, Young modulus and yield strength, as a function of pressure for different loads. An increase of microhardness, Young's modulus and yield strength was observed with increasing pressure from $0.3 \mathrm{GPa}$ to $0.9 \mathrm{GPa}$. This result indicates that an enhancement of the pressure work on article contacts which get rearranged to fill the voids and pores resulting in more densification of the specimen [11], which leads to a remarkable increase in the mechanical resistance of the samples. On the other side an increase of pressure to $1.1 \mathrm{GPa}$ reduces the mi- crohardness, Young's modulus and yield strength. This decrease of mechanical properties is due to the decrease in strength of bonding between the grains and consequently causes the degradation [12].

\section{Conclusions}

1) The highest critical temperature was $117 \mathrm{~K}$ under $0.7 \mathrm{GPa}$.

2) A remarkable increase, in the mechanical resistance of the samples was observed with the increase of the pressure from $0.3 \mathrm{GPa}$ to $0.9 \mathrm{GPa}$. On the other hand an increase of the pressure to $1.1 \mathrm{GPa}$ reduces these properties.

\section{REFERENCES}

[1] T. D. Xiao, K. E. Gonsalves and P. R. Strutt, "Synthesis of Aluminum Nitride/Boron Nitride Composite Materials," Journal of the American Ceramic Society, Vol. 76, No. 4, 1993, pp. 987-992. doi:10.1111/j.1151-2916.1993.tb05323.x 
[2] P. L. Chen and I. W. Chen, "Sintering of Fine Oxide Powders: I, Microstructural Evolution," Journal of the American Ceramic Society, Vol. 79, No. 12, 1996, pp. 31293135. doi:10.1111/j.1151-2916.1996.tb08087.x

[3] D. R.Yang, D. S. Tsai and H. C. Liu, "Raising Pyrolysis Yield of Preceramic Polymers of Silicon Carbonitride," Journal of Material Science, Vol. 30, No. 17, 1995, pp. 4463-4468. doi:10.1007/BF00361532

[4] B. S. Ahn, "Synthesis of $\mathrm{BiSrCaCu}(\mathrm{Ni}) \mathrm{O}$ Ceramics from the Gel Precursors and the Effect of Ni Substitution," Bulletin Korean Chemical Society, Vol. 23, No. 9, 2002, pp. 1304-1308. doi:10.5012/bkcs.2002.23.9.1304

[5] J. Joo, J. P. Singh, T. Warzynski, A. Grow and R. B. Poeppel, "Role of Silver Addition on Mechanical and Superconducting Properties of High- $\mathrm{T}_{\mathrm{c}}$ Superconductors" Applied Superconductivity, Vol. 2, No. 6, 1994, pp. 401410. doi:10.1016/0964-1807(94)90087-6

[6] K. Katagiri, A. Murakami and K. Kasaba, "Evaluation of Mechanical Properties of High-Temperature Superconducting Bulks Fabricated by a Melt-Processing," Cryogenics, Vol. 48, No. 3-4, 2008, pp. 87-94. doi:10.1016/j.cryogenics.2008.02.003

[7] M. A. Madre1, Sh. Rasekh, J. C. Diez and A. Sotelo, "Dynamic Fatigue Behaviour of Ag-Doped Bi-2212 Tex- tured Thin Rods," Journal of Physics: Conference Series, Vol. 153, No. 1, 2009, Article ID: 012021.

[8] G. Y. Hermiz, B. A. Aljurani and H. A. Thabit, "Mechanical Properties of $\mathrm{Bi}_{1.6} \mathrm{~Pb}_{0.4} \mathrm{Sr}_{1.8} \mathrm{Ba}_{0.2} \mathrm{Ca}_{2} \mathrm{Cu}_{3-\mathrm{x}} \mathrm{Ni}_{\mathrm{x}} \mathrm{O}_{10+\delta}$ Superconducting System," Journal of Superconductivity and Novel Magnetism, Vol. 25, No. 6, 2012, pp. 16291634. doi:10.1007/s10948-012-1584-3

[9] X. J. Chen, H. Q. Lin and C. D. Gong, "Pressure Dependence of T(c) in Y-Ba-Cu-O Superconductors," Physical Review Letter, Vol. 85, No. 10, 2000, pp. 2180-2183. doi:10.1103/PhysRevLett.85.2180

[10] S. V. Vonsovsk, Yu. A. Lzumov and E. Z. Kurmaev, "Superconductivity of Transition Metals," Springer-Verlag, Berlin, 1982.

[11] V. M. Anandakumar and M. A. Khadar, "Microhardness Studies of Nanocrystalline Calcium Tungstate," Crystal Research and Technology, Vol. 43, No. 2, 2008, pp. 193199. doi:10.1002/crat.200710987

[12] O. Gorur, M. Nursoy, C. Terzioglu, A. Varilci and I. Belenli, "Influence of Annealing Temperature on the Microstructure and Mechanical Properties of $\mathrm{MgB}_{2}$," Journal of Physics: Conference Series, Vol. 153, No. 1, 2009, Article ID: 012012. 